\title{
Mortality evolution in Algeria: What can we learn about data quality?
}

\author{
Farid Flici $^{1, *}$ and Nacer-Eddine Hammouda ${ }^{2}$
}

\begin{abstract}
Mortality in Algeria has declined significantly since the country declared its independence in 1962. This trend has been accompanied by improvements in data quality and changes in estimation methodology, both of which are scarcely documented, and may distort the natural evolution of mortality as reported in official statistics. In this paper, our aim is to detect these methodological and data quality changes by means of the visual inspection of mortality surfaces, which represent the evolution of mortality rates, mortality improvement rates and the male-female mortality ratio over age and time. Data quality problems are clearly visible during the 1977-1982 period. The quality of mortality data has improved after 1983, and even further since the population census of 1998, which coincided with the end of the civil war. Additional inexplicable patterns have also been detected, such as a changing mortality age pattern during the period before 1983, and a changing pattern of excess female mortality at reproductive ages, which suddenly appears in 1983 and disappears in 1992.
\end{abstract}

Keywords: mortality; Algeria; Lexis map; data quality; methodological change; vital statistics

\section{Introduction}

Mortality analysis remains a common approach to assessing the efficiency of public health programs (Purdy et al. 2013) and related improvements in the living conditions of a given population (Elo and Preston 1992). The quality and validity of such analyses relies to a large extent on the quality of the underlying data, which is often far from perfect in the context of developing countries. Thus, whenever

\footnotetext{
${ }^{1}$ Research Center in Applied Economics for Development (CREAD), Algiers, Algeria.

${ }^{2}$ National Committee for Population, Health Ministry, Algiers, Algeria.

${ }^{*}$ Correspondence to: Farid Flici, farid.flici@ cread.dz
} 
possible, it is essential to assess, evaluate and correct these data, as well as estimates based on these data. Assessing and correcting historical mortality estimates is, however, very complex when the crude data used to estimate mortality indicators are not provided, or when the methods used to correct and adjust crude counts are not well known. In such cases, the regularity of the time series of mortality indicators can be used to detect data quality or methodological issues (Rey et al. 2011). In the absence of extreme events like wars, epidemics or geopolitical restructuring, the evolution of different mortality indicators over time, such as life expectancy, age-specific mortality rates, age patterns of mortality improvement and male-female mortality ratios, is expected to happen in a gradual and smooth fashion (Vékás 2020). Sudden changes in these indicators are often due to changes in data processing (Börger et al. 2018), or are related to data quality issues.

Our aim in this paper is to assess historical mortality estimates for Algeria, where life expectancy at birth has increased from 47 years in 1962 to 77.7 years in 2018. While there is a large body of literature on the evolution of mortality in Algeria (Salhi 1984; Daoudi 2001; Hamza-Cherif 2011), most of these studies did not analyse the effects of methodological changes or data quality on the estimated outcomes. One exception is Flici (2020), who performed a change-point analysis on the evolution of life expectancy at birth for the Algerian population from 1977 to 2018 , both sexes combined (Figure 1). The aim of the change-point analysis was to detect significant changes in the general life expectancy level, and its improvement rate. The analysis concluded by splitting the series of life expectancy at birth, initially assumed to be of an S-logistic shape, into S-logistic segments separated by four change-points corresponding to 1983, 1992, 1998 and 2008. Except for a

\section{Figure 1:}

Evolution of life expectancy at birth (Algeria: 1962-2018) fitted using S-logistic segments

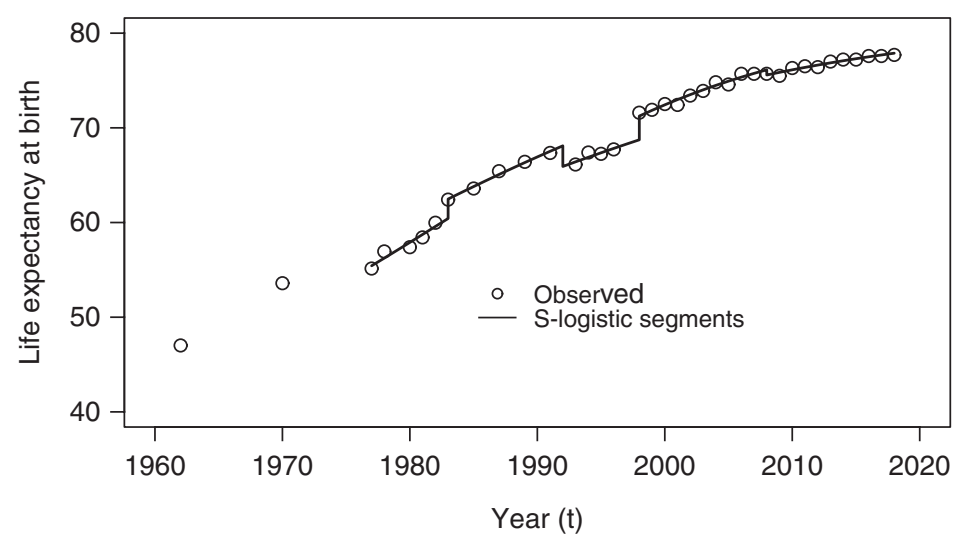

Source: Flici (2020). 
steep decline in survival due to the civil war between 1992 and 1998, all of the change-points could be linked to methodological modifications in the estimation of life expectancy. For example, one change-point in 1983 was attributable to an update of the correction factors for death registration incompleteness, and, ultimately, to a change in mortality adjustment methods. Similarly, a change-point in 2008 was due to an update of the population structure based on the census data collected in the same year. Even the observed decline in survival related to the civil war was amplified by changes in the data and methods used for the estimations.

While change-points analyses like that of Flici (2020) can be useful for detecting points in time when general mortality increases (or decreases) significantly due to either mortality shocks or methodological changes, this method is not able to detect all of the data quality problems in the Algerian context, as some significant changes could still be hidden in the mortality age pattern even after a change-point analysis of life expectancy trend has been conducted. In this paper, we seek to fill this gap by investigating the changes that occurred in the mortality age pattern of the Algerian population from 1977 to 2018. Thus, our study is intended to complement the analysis by Flici (2020). In particular, we focus on the break points that have already been defined (i.e., 1983, 1992, 1998 and 2008), and on the inter-break-points periods. We propose the use of data visualisation techniques, not only to study natural variations of mortality, but also, and more importantly, to detect changes that may reflect methodological changes or data quality issues. To this end, we visually inspect a variety of indicators in order to detect any unexpected, irregular or inexplicable patterns over age or over time: namely, the mortality age pattern, the age pattern of mortality variation rates and the male-female mortality ratios.

Shedding light on the unexpected and inexplicable patterns of the different mortality indicators may help to correct the historical evolution of mortality indicators as reported in official statistics, and to better separate the natural evolution of these indicators from the effects of methodological and data quality changes. Our aim is to make evaluating public health policies using mortality indicators more relevant and more pertinent. In addition, we expect that improving the quality and the stability of historical data will improve the robustness of mortality forecasts.

In Section 2 of this paper, we provide a short literature review of analyses of mortality patterns using data visualisation techniques, and we briefly discuss the potential sources of bias when estimating life tables using incomplete data. Next, we describe the Algerian mortality data, and we present the data visualisation methods we use to highlight the methodological changes and the data quality imperfections in the Algerian context. We then present our results in Section 3, and discuss our findings in Section 4. 


\section{Material and methods}

\subsection{Analysing mortality patterns using data visualisation techniques}

Since the emergence of demography as a science, graphical representations have attracted considerable interest as tools of analysis. This interest further expanded in the second half of the $19^{\text {th }}$ century (Caselli and Enzo 1990), which led to the development of the well-known concept of the 'Lexis diagram' (Lexis 1875), a two-axes plane that crosses time (jointly with the year of birth) and age, and that represents the survivorship and deaths of a group of individuals (Keiding 1990). Arthur and Vaupel (1984) used the term 'Lexis surface' to describe a two-axes plane (age vs. time) representing demographic rates or counts (Vaupel et al. 1987), which are also called a 'demographic surface' or a 'population surface' (Vaupel et al. 1985). The concept of a 'mortality surface' was used by Vaupel et al. (1985) to specify mortality-related measures. Gambill and Vaupel (1985) and Gambill et al. (1985) also employed an improved version of the 'contours map' from Delaporte (1942) to visualise different mortality and demographic measures.

As well as focusing on visualising mortality indicators such as death counts, life expectancy by age, changes in life expectancy by age and cause-specific mortality rates, Vaupel et al. (1987) extended the techniques to visualise other demographic measures, such as population distributions, fertility rates and the ratio of males to females in a population. Likewise, Wilmoth (1985) used Lexis maps to separate age, period and cohort effects on mortality, while Caselli et al. (1985) used the same technique to analyse mortality in Italy. Moreover, Gambill et al. (1986b) used this technique to analyse cause-specific mortality in Japan.

In addition to representing a pertinent tool for mortality data visualisation (see, for example, Aburto and van Raalte 2018; Remund et al. 2018; Rau et al. 2018), Lexis maps have, in recent years, regained their place as a tool for mortality analysis (Minton et al. 2013; Minton 2014; Vanderbloemen et al. 2016; Minton et al. 2017), with some enhancements being introduced mainly through computer software developments. For example, Minton et al. (2017) compared excess mortality in Scotland with that in the UK as a whole and in other Western European countries based on a visual inspection of the Lexis map representing the mortality ratios between the populations for the period from 1950 to 2010. Their aim was to detect through visual inspection unexpected patterns or patterns showing age, time or cohort dependence.

In this paper, we use a similar approach. We start by visualising the Lexis map of mortality rates in logarithm form for the $0,1-4$ and 5-9 age groups, and then by fiveage intervals until the 74-79 age group, for the period from 1977 to 2018, for males and females combined. We then analyse the Lexis maps of the mortality variation rates (mortality variation surface) and of the male-female mortality ratios (sex ratio mortality surface). These analyses are complemented with numerical analyses and 
simple plots when needed. All of the Lexis map type visualisations presented in this paper have been created using the R-package 'plot3D'.

\subsection{Potential sources of bias when estimating life tables based on crude data}

In this subsection, we describe the various steps of the process, starting with collecting crude data from the civil registration system to estimating national life tables. We also discuss the shortcomings in this process that have the potential to bias the final estimates. In particular, irregularities can stem from death counts and their corrections, population data and related adjustments, and model life tables (MLTs).

The life tables are calculated based on the death counts and the population numbers distributed by age and sex (United Nations 1961). These death counts are frequently drawn from the crude numbers reported to the civil registration system, and are corrected for incompleteness when death registration is not complete. Such corrections can usually be made using either survey-based estimations (Moriyama 1990) or indirect methods (Brass 1975; Preston and Hill 1980; Preston et al. 1980; Adair and Lopez 2018).

As is the case in many developing countries, in Algeria, the completeness of death registration has improved significantly since the 1970s, but has historically been low. According to estimates of the Multi Rounds Demographic Survey (MRDS1970), death registration completeness in Algeria was 60.6\% in 1970 (Daoudi 2001), had increased to nearly $64 \%$ by 1977 , and remained at approximately that level in 1978 and 1980 (Daoudi 2001; Hamza-Cherif 2011). The Workforce and Demography Survey of 1982 provided a survey-based estimation of death registration completeness for 1981 of around $81 \%$ (Daoudi 2001). If we assume that the estimates for 1981 are more reliable than those for the 1977-1980 period, then the sudden jump observed in 1981 may be attributed to the underestimation of death registration completeness for the previous period (Daoudi 2001). This pattern should, in turn, lead to an underestimation of life expectancy for the same period that should be offset when the new correction factors have been introduced. However, the death registration completeness rates for 1981 were used by the Office of National Statistics (ONS) to correct the crude death counts in response to the death registration incompleteness only from 1983 onwards (Flici 2020). The same correction factors were used continuously, without any updates, until 2002, when the Algerian Family Health Survey was conducted (ONS 2003). The new correction factors have been applied with retroactive effect from 1998 onwards, and are still being used to adjust registered deaths (ONS 2020), without being published.

In contrast to deaths, which are continuously recorded by the civil registration system, population censuses are usually taken every 10 years. In Algeria, five previous population censuses were conducted in 1966, 1977, 1987, 1998 and 2008. A sixth census is currently being performed, and the results of this census are 
expected to be available by the end of 2021. The population age structure during the intercensal periods is usually estimated by making projections based on past trends (ONS 2005; 2008); based on vital statistics, while assuming zero net migration (ONS 2003; 2020); or simply by assuming that the population age structure remains constant between censuses (ONS 2010). Usually, gaps arise when old estimates are compared to those provided by new censuses, which can lead to some irregularities and jumps in mortality indicators over time (Flici 2020).

In Algeria, as in many other developing countries, another fundamental step involved in constructing national life tables is using regional model life tables (MLTs) to adjust the curve of age-specific mortality when it is irregular, or does not follow a conventional shape (Mouffok 1984). Several MLT systems have been developed for this purpose, such as the United Nations MLTs (United Nations 1982) and the MLTs of Princeton (Coale and Demeny 1966; Coale et al. 1983; Coale and Guo 1989). In addition to the effect on life expectancy estimates of the choice of the MLT (McCaa 1978), a change in the choice of the MLT system - or in the group of MLTs within the same system - used for adjustment can lead to inconsistencies in the life expectancy time series. This kind of effect was observed in Algeria in 1983, when there was a sudden jump that was mainly attributable to a change in the MLT used, as reported by Flici (2020).

\subsection{Data}

To assess the irregularities related to data quality and estimation methods in mortality estimates for Algeria, we use the national life tables published annually by the ONS from 1977 to 2018. The abridged life tables are published for males, females and the total population at ages zero, 1-4 years and then by five-age intervals until the open age group, which has been varying irregularly from 70 years and older to 85 years and older. From 1998 onwards, these national life tables have been published annually. Before 1998, there were no published life tables for some years; namely, for 1979, 1984, 1986, 1988, 1990, 1992 and 1997.

\subsection{Estimating and visualising mortality estimates}

For our analysis, a complete mortality surface is required, or the missing calendar years life tables need to be estimated. In addition, based on a common closure age of 80 years for the whole mortality surface, the life tables closed out at younger ages need to be extended up to 80 years. To this end, we propose extending the life tables closed out earlier than at age 80 using the Gompertz model (Gompertz 1825). Consequently, we estimate the mortality rates for the 70-74 and 75-79 age groups for the years 1983, 1985 and 1987, and the mortality rates for the 75-79 age group for the 1993-1996 period. Then, we estimate the missing life tables for 1979, 1984, 1986, 1988, 1990, 1992 and 1997 using linear interpolation. It is important to note that the life table for 1998 was first published in 1999, and was revised in 2002 using 
the death completeness rates estimated in 2002, combined with the population age structure from the population census of 1998. Thus, there are two versions of the life table corresponding to 1998. In order to estimate the life table for 1997 using linear interpolation between 1996 and 1998, it is advisable to use the old life table for 1998, rather than the revised life table.

While analysing mortality surfaces is supposed to provide a general overview of mortality improvements, especially during the periods when mortality shocks occurred, some effects may be hidden from the reader. Hence, it is necessary to complement the analysis using other indicators. Visualising the Lexis diagram of the mortality variation rates with the age groups on the vertical axis and the time on the horizontal axis is assumed to highlight the ages for which drastic changes were recorded during the studied periods, and the time periods for which unexpected changes were recorded. We consider ${ }_{n} Q_{x, t}$ the mortality rate of the age group [ $x, x+n$ [ during the year $t$. The age $x$, in our case, is equal to $0,1,5$, and then to a step of five years. The year $t$ goes from 1977 to 2018. A mortality variation rate is defined by

$$
{ }_{n} V_{x, t}=\frac{{ }_{n} Q_{x, t}}{{ }_{n} Q_{x, t-1}}-1
$$

We note that the mortality variations rates are estimated for males and females combined.

The colour scale of the resulting mortality variation surface is defined in order to distinguish different degrees of variation: a slight reduction $\left(-5 \%<{ }_{n} V_{x, t}<0 \%\right)$, a moderate reduction $\left(-10 \%<{ }_{n} V_{x, t} \leq-5 \%\right)$, a sharp reduction $\left({ }_{n} V_{x, t} \leq-10 \%\right)$, stagnation or a slight increase $\left(0 \% \leq{ }_{n} V_{x, t}<10 \%\right)$, a significant increase $(10 \% \leq$ $\left.{ }_{n} V_{x, t}<20 \%\right)$, a sharp increase $\left(20 \% \leq{ }_{n} V_{x, t}<40 \%\right)$ and, finally, a drastic increase $\left({ }_{n} V_{x, t} \geq 40 \%\right)$. In addition, contours are plotted around variation rates of $+10 \%$ and $-10 \%$ to better visualise large variations.

In order to continue with the mortality variation analysis, and considering the change-points already defined by Flici (2020), we visualise the age pattern of mortality variation at the change-points compared to during the inter-change-points periods. Using simple plots, this step aims to detect changes in the age pattern of mortality variation from one period to another, and to detect the ages that benefited the most from mortality reduction over time. In addition, this step seeks to visualise the effects of mortality shocks and methodological changes on the different age groups.

Another way to complement the mortality surface analysis is to visualise the male-female mortality ratio surface for $t$ from 1977 to 2018, and for the ages $0,1,5,10, \ldots, 75$ years. The male-female mortality ratio, noted as ${ }_{n} R_{x, t}$, is calculated by the ratio of the male mortality rate at the age group $[x, x+n$ [ during the year $t$ to the corresponding female mortality rate. It can be written as ${ }_{n} R_{x, t}={ }_{n} Q_{x, t}^{m} /{ }_{n} Q_{x, t}^{f}$ with $m$ and $f$ refering to male and female, respectively. The visualisation of the Lexis diagram of ${ }_{n} R_{x, t}$, or the mortality sex ratio surface, as in Rigby and Dorling (2007), 
is assumed to highlight unexpected patterns caused by the effects of the methodological changes and the data imperfections.

Differences in mortality by sex have been linked to a set of environmental factors (Crimmins et al. 2019), biological differences (Kruger and Nesse 2004; Rogers et al. 2010) and, more importantly, differences between males and females in risktaking behaviour (Rigby and Dorling 2007). All over the world, females generally have longer life expectancy at birth than men (Population Reference Bureau [PRB] 2020), but mortality can be higher for females than for males at certain ages during specific periods of time (Wisser and Vaupel 2014). The male-female gap in life expectancy at birth ranges from one year (e.g., Algeria, Burkina Faso) to 10 years (e.g., Ukraine, Russia) (PRB 2020). In most industrialised countries, the life expectancy gap between males and females was increasing until the 1980s, and started decreasing thereafter (Meslé 2004).

Building on the historical evolution of the age pattern of male-female mortality and the life expectancy gap between males and females, several different patterns have been observed since the beginning of the $21^{\text {st }}$ century. Thus, analysing sex ratios can shed light on the unexpected patterns that arise due to data quality issues or changes in the vital registration system.

\section{Results}

\subsection{The mortality surface}

In an initial visual inspection of Figure 2, two general aspects of the evolution of mortality in Algeria are apparent: i.e., there has been a general improvement in mortality over time, and a continuous increase in mortality with age. Very high mortality rates are shown in red, while the lowest rates are displayed in dark blue. Accordingly, we can see that an individual is less likely to die at ages 5-9 years than $\mathrm{s} / \mathrm{he}$ is during the rest of his/her life course. The increasing intensity of the blue colour over the years reflects decreasing mortality rates. The rising contour lines indicate an augmentation of the age at which a given level of mortality is reached. When the contour lines are distanced by one in a logarithmic scale, the rates return to levels multiplied by 2.72 in the real scale. This means that the levels defined by $-6,-5,-4,-3,-2$ and -1 in Figure 2 correspond to mortality rates of 0.0025 , $0.0067,0.0183,0.0498,0.1353$ and 0.3678 , respectively.

Nonetheless, the effect of the civil war during the 1990s is visible between ages 15 and 49. The decline of the contour line corresponding to $\log \left({ }_{n} Q_{x}\right)=-5$ starting in 1992 means that this mortality level, corresponding to ${ }_{n} Q_{x}=0.0067$, was crossed at earlier ages than usual: i.e., around age 20, on average, during the 1992-1997 period, compared around age 25 during the preceding years. The line corresponding to -4 , which is situated at relatively higher ages, marks a smaller decline, which means that the effects of the civil war were less meaningful at around ages 40 and 49 than they were at younger ages. 


\section{Figure 2:}

The surface of five age log mortality rates (Algeria: 1977-2018)

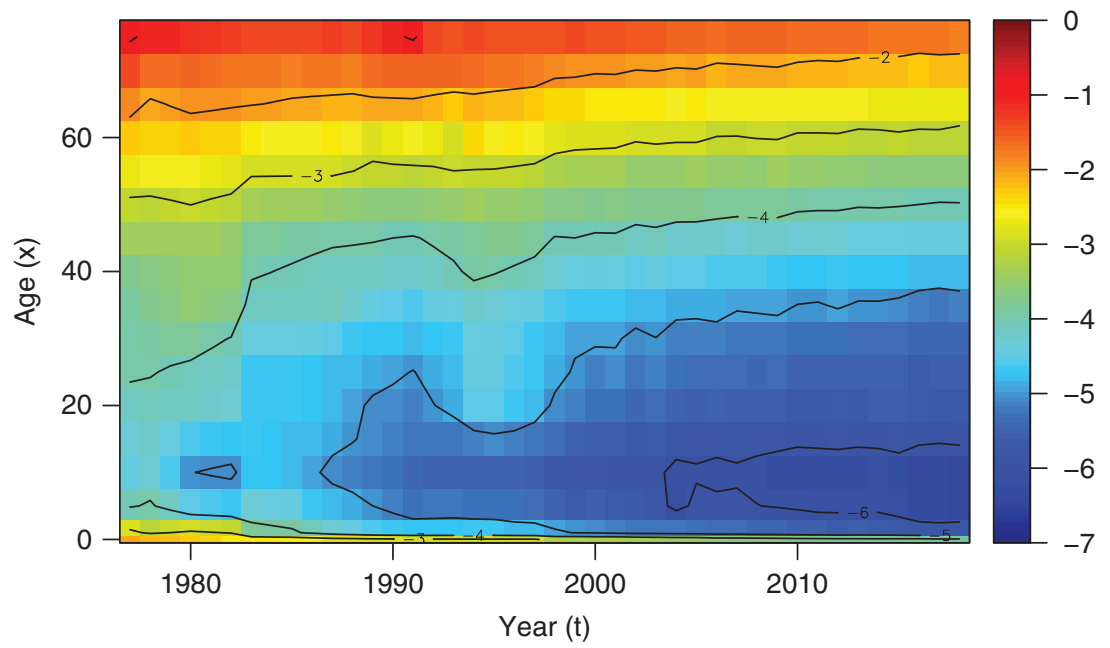

Sources: Authors' computations based on data provided by ONS (2012) for 1977-2011; ONS annual publications for 2012-2018. Missing data were estimated by extrapolation and interpolation.

Moreover, in Figure 2, the disconnection of the map shade in 1983 reflects a sharp increase in mortality at ages five to 19 , accompanied by a sharp decrease in mortality at ages 20 and older.

\subsection{Mortality reduction}

Figure 3 shows the annual rates of variation in mortality rates, which range from a minimum of $-53 \%$ (indicating that mortality decreased, or improved, by one-half) and a maximum of $+67 \%$ (indicating that mortality increased by two-thirds). The colour scale ranges from dark blue, representing a significant reduction in mortality; to dark red, representing a significant increase in mortality. Contour lines were added at the levels corresponding to $+10 \%$ and $-10 \%$.

Between 1977 and 1978, mortality decreased at ages 0-4, while it increased significantly at ages 5-19. This pattern was reversed in the 1979-1980 period, and mortality returned to decreasing moderately in the 1981-1982 period. Among the 30-44 age group, mortality was increasing noticeably from 1978 to 1980. In 1983, the different age groups reacted very differently to the general evolution of mortality: i.e., mortality suddenly decreased by more than one-half in the 1-4 age group; it increased by more than $30 \%$ in the 5-9 age group and by $60 \%$ in the 10-14 age group; and it declined by between $10 \%$ and nearly $50 \%$ in the 15-64 age group. 
Figure 3:

Mortality variation surface (Algeria: 1977-2018)

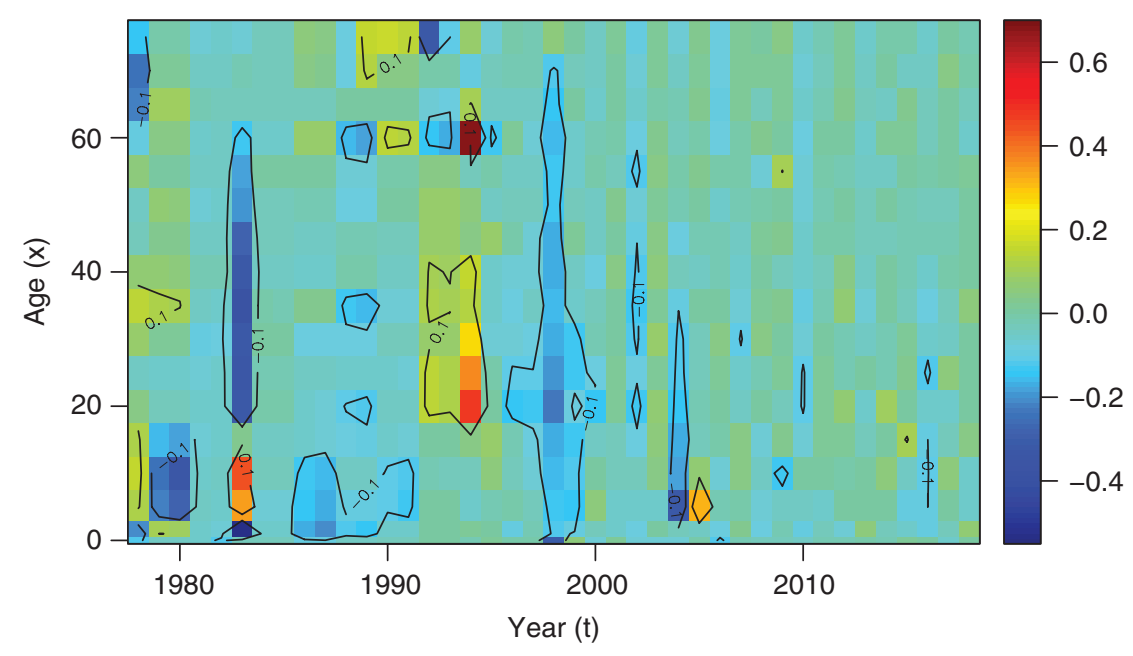

Sources: Authors' computations based on data provided by ONS (2012) for 1977-2011; ONS annual publications for 2012-2018. Missing data were estimated by extrapolation and interpolation.

Note: Mortality variation rates are calculated as the rate of increase/decrease in mortality rates for the different age groups between years $(t-1)$ and $t$. The figure shows a variation interval ranging from $-53 \%$ (blue) to $+67 \%$ (red) The contours indicate the variations surpassing $10 \%$ (in both senses).

Almost all age groups experienced slight reductions in mortality from 1983 to 1991, and mortality declined rapidly in the 1-14 age group from 1983 to 1991 .

After the start of the civil war in 1992, mortality increased in all age groups between zero and 49 years (except at ages 10-14), and especially at ages 20-44. A similar pattern was observed in 1993 and 1994, reflecting increases in the intensity of violence, which reached peak levels in 1994. Mortality was at approximately the same level in 1994 and 1995. In 1996 and 1997, mortality was decreasing steadily at all ages, but most significantly in the 20-29 age group.

In 1998, a sharp decline in mortality was observed at all ages, which means that there was a general decrease in mortality. In 1999, mortality continued to improve significantly for some age groups, and especially from ages one to 34 years. Thereafter, the evolution of mortality was more regular than it had been before 1998. However, sharp reductions in mortality can be observed during certain years in certain age groups: e.g., in the 20-44 age group in 2002, and in the 5-39 age group in 2004.

Figures 4 and 5 display the five-year age average variation of mortality rates by period, and the age pattern of mortality variation at the change-points defined by Flici (2020) based on the S-logistic segmentation. The analysis of the evolution of mortality rates by age revealed that the $1-4$ age group benefited the most from the 
Figure 4:

Annual variation of mortality rates by sub-periods (Algeria: 1977-2018)

(a)

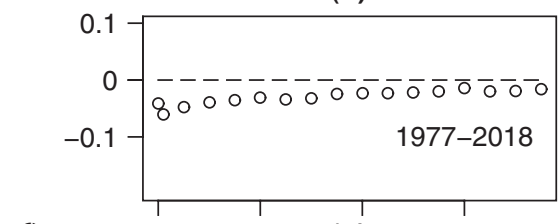

(c)

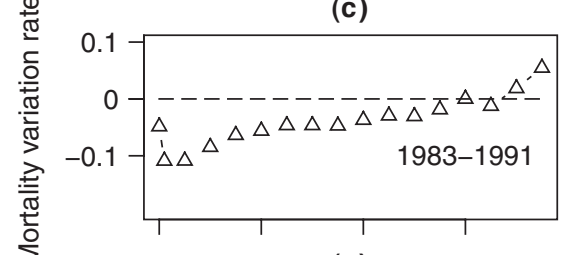

(e)

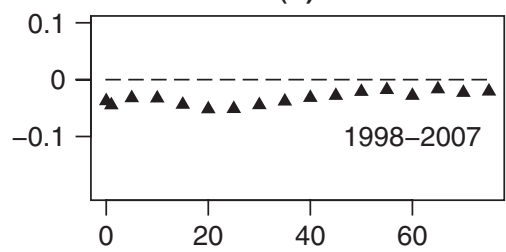

(b)

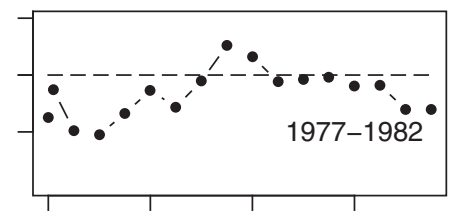

(d)

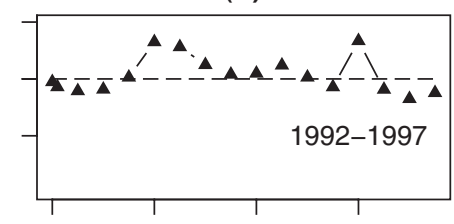

(f)

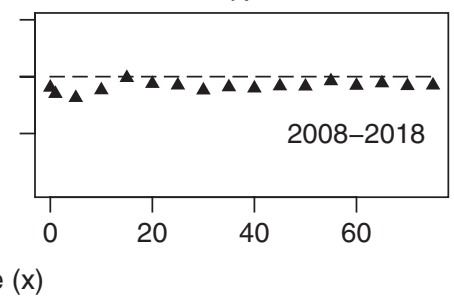

general improvements in mortality from 1977 to 2018, with an average annual rate of mortality reduction of 6\% (Figure 4(a)); followed by the 5-9 age group, with a rate of nearly $5 \%$; and by age zero, with a rate of $4.2 \%$. The average annual rates of mortality reduction during this period for the other age groups were as follows: between $3 \%$ and $4 \%$ for the 10-34 age group, between $2 \%$ and $2.5 \%$ for the $35-54$ age group, and between $1 \%$ and $2 \%$ for the $55+$ age group. Thus, we can conclude that the younger age groups benefited more than the older age groups from the general improvement in mortality.

When we look at the age patterns of the average rates of mortality reduction during the 1983-1991 (Figure 4(c)), 1998-2007 (Figure 4(e)) and 2008-2018 (Figure 4(f)) periods, we see that the pace of mortality reduction was decreasing over time, and that the rate was generally decreasing with age. The average age patterns displayed during the 1977-1982 (Figure 4(b)) and 1992-1997 (Figure 4(d)) periods differed significantly from those in the other periods. This was likely due to the high variability of the age pattern of mortality variation, which was changing substantially in the abovementioned periods. Hence, simply estimating average patterns would have hidden these complex age patterns.

On the other hand, the decomposition of the change-point of 1983 (Figure 1) into age-specific variation (Figure 5(a)) revealed a sharp reduction in mortality at 
Figure 5:

Annual variation of mortality rates in 1983, 1992, 1998 and 2008

(a)

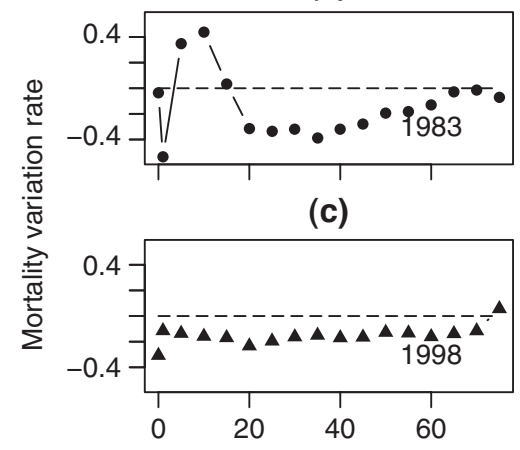

(b)

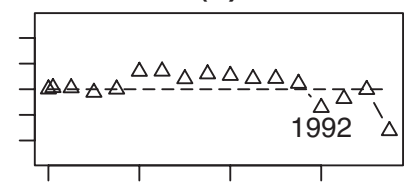

(d)

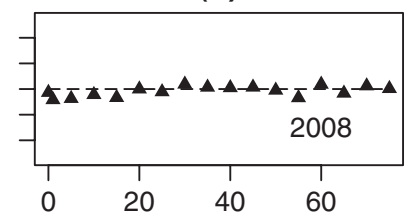

Age (x)

ages 20 and older, accompanied by a significant increase in the 5-14 age group. Figure 5(d) provides some insights that cannot be gleaned by simply looking at the mortality variation surface (Figure 3), even if a change-point for the evolution of life expectancy at birth in that year could be observed (Figure 1). In 2008, the average rate of mortality reduction fell to $1.7 \%$, after it was $3.3 \%$, on average, during the 1999-2007 period. This sudden decline in the general mortality reduction rate was accompanied by a slight distortion of the age pattern, as the rate of mortality reduction for the 1-19 age group suddenly jumped to nearly $7 \%$, from half that level during the previous period. By contrast, the rate of mortality for the 30-49 age group unexpectedly increased by nearly $+2 \%$, after decreasing at an average rate of $3.6 \%$ during the previous period.

\subsection{The evolution of the male-female differential mortality}

The gap in life expectancy between males and females and the mortality sex ratio (MSR) represent complementary tools for measuring death registration completeness (Tabutin 1991). When we look at the evolution of male and female life expectancy (Figure 6), we can see that the two curves have followed similar trends, maintaining an average gap of 1.65 years, which is much smaller than the gaps observed in other North African countries (Tabutin and Schoumaker 2005).

Between 1977 and 2018, men gained 23 additional years of life expectancy from 54.2 to 77.1 years; with an average annual gain of 204 days per year. Women gained slightly fewer years of additional life expectancy (22.3 years), from 56 to 78.4 years; with an average annual gain of 198.5 days per year. The gender gap in life expectancy was as large as 2.5 years in the period before 1983. The gap narrowed by $60 \%$ in the following period, and had reached 0.3 by 1989 . The gap widened 
Figure 6:

Male-female differentials in the evolution of life expectancy (Algeria: 1977-2018)
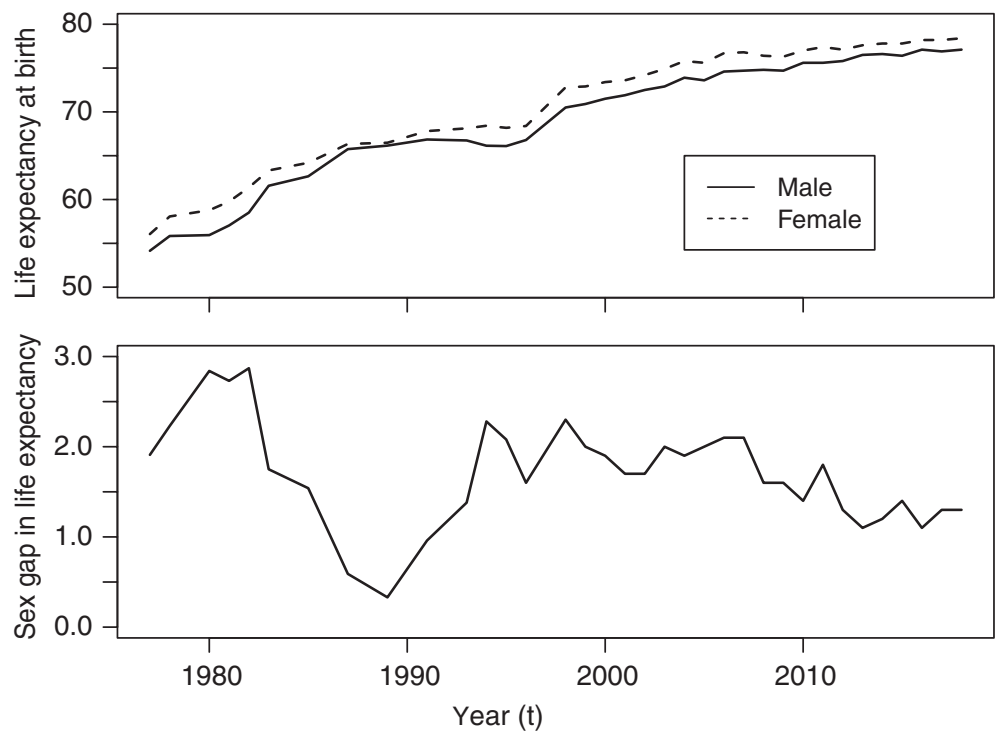

Sources: Authors' computations based on data provided by ONS (2012) for 1977-2011; ONS annual publications for 2012-2018. Missing data were estimated by interpolation.

again starting in 1989, reaching 2.3 in 1994, the year when mortality associated with the civil war reached its highest level. After 1994, the gap gradually narrowed, declining to 1.3 by 2018 .

Figure 7 shows the male-female mortality ratio from 1977 to 2018 for ages zero, 1-4 and 5-9, and then by five-age groups until ages 75-79. Excess female mortality can be observed in many sub-surfaces of the Lexis map marked with dark blue: i.e., between ages 20 and 29 in 1977 and between ages 30 and 44 in the following year. The 20-29 age group almost returned to having excess female mortality during the 1983-1988 period. For the 30-49 age group, excess female mortality was observed between 1989 and 1991. Moreover, excess female mortality was recorded for the 1-4 age group until 1998, and extended up to age 14 in 1981 and to age nine during the 1986-1990 period.

In addition, until 1982, relatively high excess male mortality was observed: i.e., high excess male mortality was detected in the 45-59 age group in 1977, in the 55-74 age group in 1978 and 1979, and in the 35-64 age group from 1980 to 1982.

The effects of the civil war on the male-female mortality gap were noticeable starting in 1992 with the 20-29 age group, and spread rapidly in the following years to the 15-34 age group. In 1994 and 1995, men aged 20 to 29 were two to three 
Figure 7:

Mortality sex ratio surface (Algeria: 1977-2018)

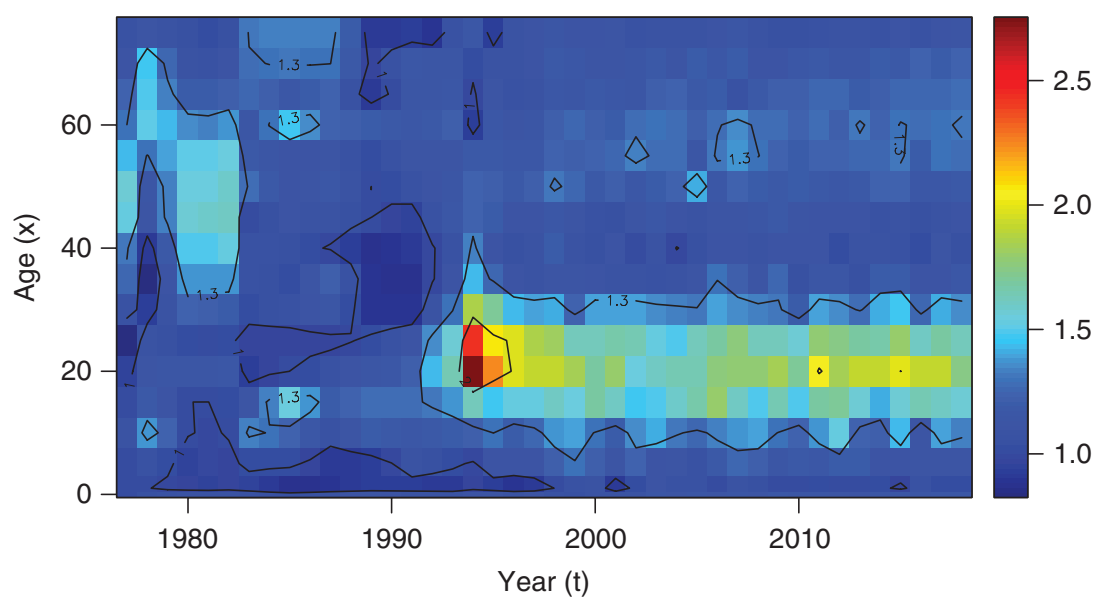

Sources: Authors' computations based on data provided by ONS (2012) for 1977-2011; ONS annual publications for 2012-2018. Missing data were estimated by extrapolation and interpolation.

Note: The mortality sex ratio at age $x$ and time $t$ is calculated by the ratio of the male mortality rate at age $x$ and time $t$ to the female mortality rate at age $x$ and time $t$. Male mortality is usually slightly higher than female mortality. The plot shows that the MSR ranged from slightly less than one with excess female mortality, to more than 2.5 (dark red) with excess male mortality. The contours lines mark the one, 1.3 and two levels.

times more likely to die than their female counterparts. After the civil war ended, the male-female mortality ratio among the 15-34 age group decreased, but was still larger than it was in the other age groups, and than it was before the start of the civil war.

\section{Discussion}

The aim of this paper was to assess the Algerian mortality data between 1977 and 2018 based on a visual inspection of Lexis maps representing different mortality indicators over age and time. Thus, we sought to complement the findings by Flici (2020), who detected important level jumps and slope changes attributable to methodological changes and data quality issues. Our analysis contributed to research on this topic by further considering variations in the mortality age patterns, which led to important additional insights into the evolution of life expectancy in Algeria. Overall, mortality rates in Algeria were decreasing over time, but the younger age groups benefited much more from that development than the older age groups, as the pace of the mortality decline decreased substantially with age. Our assessment of the quality of the mortality data represents a fundamental step towards 
evaluating the efficiency of public health policies. The main assumption we adopted was that under normal conditions - i.e., in the absence of mortality shocks - the evolution of mortality indicators should be gradual and smooth. Thus, we assumed that any irregular and unexpected patterns were likely attributable to the effects of methodological changes or data quality issues.

Our analysis of the mortality surface, the mortality variation surface and the male-female mortality ratios surface revealed that the different mortality measures were more stable after than before 1998. This pattern can be linked to data quality improvements and the relative stability of the methodology used to construct national life tables. Indeed, death registration completeness and the quality of population estimates were much better after 1998 than they were during the civil war (1992-1997) or in the preceding period. Overall, we found clear signs of data quality improvements over time, which means that the vital statistics have also become more reliable. Thus, official statistics no longer have to depend solely on indirect estimation techniques to derive measures of mortality.

The high variability of the mortality age pattern we observed during the 19771983 period, which was more evident on the mortality variation surface, might be attributable to changes in the methodology for the adjustment of the crude mortality curves using the MLTs. In addition to the opposite variations in mortality rates at the different ages, we observed extreme reversals of trends over time. Similar changes in patterns were detected on the sex ratio surface. In addition, we found evidence that death registration completeness was underestimated in the period before 1983 . Indeed, the completeness rates for 1977-1980, which were not obtained through a specific survey (Hamza-Cherif 2011), were estimated to be merely 64\%, whereas the Workforce and Demography Survey provided a completeness rate estimate of $81 \%$ for the year 1981 (Daoudi 2001). If death registration completeness was underestimated during the 1977-1982 period, given that the new rates were not used until 1983 onwards (Flici 2020), mortality should have been overestimated during that period. The revision of correction factors for incompleteness resulted in a downward shift in mortality, which is easily noticeable on the mortality surface as a cut of the evolution pattern, and on the mortality variation surface as a vertical line dominated by dark blue. Despite this overall increase in mortality observed in 1983, some age groups were found to have experienced significant decreases in mortality, which led to a distortion of the mortality curve between 1982 and 1983 . This distortion was probably due to the changes in the mortality adjustment methods, and in the group of MLTs considered adequate for Algeria.

As the mortality indicators were more stable from 1983 to 1991 , the data quality and the methods used for the estimates over this period may have been more stable as well. However, different patterns are displayed after and before 1989 on the mortality sex ratio surface. While the excess female mortality observed at reproductive ages (i.e., 15-49 years) during certain years of the period from 1983 to 1991 can be linked to the effects of maternal mortality, as the theory would suggest (De Forts 1998); the irregularity displayed around 1989 is intriguing. Despite the evidence of the importance of maternal mortality during this period, there are two 
findings that make it difficult to distinguish natural evolution from the effects of data quality: the observation that the surface delimiting excess female mortality suddenly shifted from the 20-29 age group in 1983-1988 to the 30-49 age group in 1989-1991; and the finding that this effect appeared suddenly in 1983, and then disappeared suddenly in 1992. Indeed, even in a context of high maternal mortality, changes that are driven by actual increases or decreases in mortality are not expected to be sudden, but are instead supposed to be gradual. When we looked at reductions in mortality, we found that the 1-14 age group had much larger reductions than the other age groups from 1983 to 1991.

During the civil war, there were two phases with different age patterns of mortality improvements: a phase of dramatic increases in mortality from 1992 to 1994, and then a return-to-normal phase from 1995 to 1997. Mortality due to violence affected the 15-34 age group more than the other age groups, and males more than females. In addition to the excess mortality due to violence, which has been estimated at 200,000 deaths (Kouaouci and Saadi 2013), there were other factors that may have affected data quality during the civil war in the 1990s. For example, while between 5,000 and 10,000 individuals (Martinez 2003) were reported as 'lost', it is likely that many of these people died, but their deaths were not registered. In addition, the registration of deaths and of other demographic events was made more challenging because civil service functions were disturbed by acts of terrorism. Some administrative offices, including archives, were destroyed in various cities during the civil war. These two factors, along with many others, may have led to a slight underestimation of the mortality of the Algerian population during the civil war. Unfortunately, these potential disruptions to the registration of deaths are not documented in the official publications of the ONS, or in academic papers.

Levels of violence were reduced towards the end of 1997, when a ceasefire agreement was signed between the government and one of the most important terrorist groups (International Crisis Group 2001), and mortality rates fell significantly between 1997 and 1998. However, the decline in mortality levels in 1998 was attributable not only to the end of the civil war, but also to methodological changes, particularly to the second revision of the correction factors for death registration incompleteness (Flici 2020). Using the death registration completeness rates of 1981 to correct crude counts up to 1998 should have generated an overestimation effect of corrected death counts, since coverage was assumed to have improved since then. The update of the correction factors offset the overestimating effect of the old correction factors, and led to a sudden decease in mortality. In addition, the update of the population structure using the data provided by the population census of 1998 contributed to the sudden mortality decrease in 1998. It is, however, intriguing that the sharp decline in 1998 was not visible on the mortality sex ratio surface. This jump was easily distinguishable on the mortality surface, and was much more visible on the mortality variation surface.

The period before 1998 was characterised by excess female mortality in the 1-4 age group, which extended to the 5-9 age group in some years. This is not a new phenomenon, and is less likely to be attributable to data quality issues than 
to sociological factors, such as better treatment of boys than of girls (Secrétariat d'Etat au Plan 1975), including discrimination against girls in terms of nutrition and medical care, which has sometimes been observed in traditional societies (D'Souza and Chen 1980). Tabutin (1991) found evidence of excess female mortality in the 1-4 age group in Algeria during the 1965-1977 period. Similar patterns have been observed at least until 1990 in many developing countries, including Yemen, Pakistan, Nepal, India, Bangladesh and Iran (Alkema et al. 2014); and at least until the end of the 1990s in the North African countries (Tabutin et al 2007).

After 1998, mortality was evolving at a more regular pace than it was in the period before 1998. This stability, which may reflect not only improvements in data quality, but also stability in the methodology used to construct national life tables, was easily noticeable on the mortality surface, the mortality sex ratios surface and the mortality variation surface. When we looked at the male-female mortality differential, we found that male mortality rates were significantly higher than female mortality rates at ages 15 to 34 until 2018, and that the differential was larger in this age group that it was in the other age groups. The mortality variation surface displayed some intense changes for certain ages, particularly in 2002 and 2004. The change-point observed by Flici (2020) in 2008 did not appear clearly on the mortality variation surface.

To conclude, we have demonstrated in this paper that analysing mortality evolution by age can uncover some variation patterns that cannot be observed by simply using summary mortality indicators, such as life expectancy at birth or crude mortality rates. The use of Lexis maps, or 'shaded contour maps', provides a valuable opportunity to get an informative overview of the evolution of mortality over age and time, and to detect uncommon patterns. However, when using this approach, it is necessary to compare different mortality measures, instead of relying on one measure only. Thus, visualising the mortality sex ratios surface and the mortality variation surface can help us detect certain effects that may be hidden in the mortality surface.

\section{Acknowledgements}

We gratefully thank the editors and the anonymous reviewers for their orientations, their remarks and the efforts that they have made throughout the reviewing process, which helped to improve the quality of the manuscript. Also, our special thanks go to Magali Barbieri for her remarks on a previous version of the paper.

\section{References}

Aburto, J. M. and A. van Raalte 2018. Lifespan dispersion in times of life expectancy fluctuation: the case of Central and Eastern Europe. Demography 55(6): 2071-2096. https://doi.org/10.1007/s13524-018-0729-9 
Adair, T. and A. D. Lopez 2018. Estimating the completeness of death registration: an empirical method. PloS ONE 13(5): e0197047. https://doi.org/10.1371/journal.pone. 0197047

Alkema, L., F. Chao, D. You, J. Pedersen and C. C. Sawyer 2014. National, regional, and global sex ratios of infant, child, and under-5 mortality and identification of countries with outlying ratios: a systematic assessment. The Lancet Global Health 2(9): e521-e530. https://doi.org/10.1016/S2214-109X(14)70280-3

Arthur, W. B. and J. W. Vaupel 1984. Some general relationships in population dynamics. Population Index 50(2): 214-226. https://doi.org/10.2307/2736755

Börger, M., M. Genz and J. Ruß 2018. Extension, compression, and beyond: A unique classification system for mortality evolution patterns. Demography 55(4): 1343-1361. https://doi.org/10.1007/s13524-018-0694-3

Brass, W. 1975. Methods for estimating fertility and mortality from limited and defective data. Laboratories for Population Statistic, University of North Carolina.

Caselli, G. and L. Enzo 1990. Graphiques et analyse démographique: quelques éléments d'histoire et d'actualité. Population 45(2): 399-414. https://doi.org/10.2307/1533378

Caselli, G., J. W. Vaupel and A. I. Yashin 1985. Mortality in Italy: contours of a century of evolution. Genus 41(1-2): 39-55.

Coale, A. J. and P. Demeny 1966. Regional model life table and stable populations. Princeton University Press, Princeton, New Jersey.

Coale, A. J. and G. Guo 1989. Revised regional model life tables at very low levels of mortality. Population Index 55(4): 613-643.

Coale, A. J., P. Demeny and B. Vaughan 1983. Regional model life tables and stable populations. Second Edition, London: Academic Press.

Crimmins, E. M., H. Shim, Y. S. Zhang and J. K. Kim 2019. Differences between men and women in mortality and the health dimensions of the morbidity process. Clinical chemistry 65(1): 135-145. https://doi.org/10.1373/clinchem.2018.288332

Daoudi, N. 2001. La mortalité en Algérie depuis l'indépendance. Genus 57: 109-121.

De Forts, J. 1998. Indicateurs de la santé maternelle en Algérie. Évolution de 1962 à 1992. Population 54(4): 859-873. https://doi.org/10.2307/1534563

Delaporte, P. 1942. Évolution de la mortalité en Europe depuis l'origine des statistiques. Journal de la société française de statistique 83: 183-203.

D'Souza, S. and L. C. Chen 1980. Sex differentials in mortality in rural Bangladesh. Population and Development Review 6(2): 257-270. https://doi.org/10.2307/1972730

Elo, I. and S. Preston 1992. Effects of early-life conditions on adult mortality: A review. Population Index 58(2): 186-212.

Flici, F. 2020. Analyzing the trend of life expectancy evolution in Algeria from 1962 to 2018: The S-logistic segmentation with jumps. Population Review 59(1): 56-72. https://doi.org/10.1353/prv.2020.0002

Gambill, B. A. and J. W. Vaupel 1985. The LEXIS program for creating shaded contour maps of demographic surfaces. IIASA Working Paper WP-85-094, Laxenburg, Austria: International Institute of Applied Systems Analysis. http://pure.iiasa.ac.at/id/eprint/2609/ 1/WP-85-094.pdf 
Gambill, B. A., J. W. Vaupel and A. I. Yashin 1986a. The LEXIS computer program for creating shaded contour maps of demographic surfaces. IIASA Working Paper WP-86-037, Laxenburg, Austria: International Institute of Applied Systems Analysis. http://pure.iiasa.ac.at/id/eprint/2822/1/WP-86-037.pdf

Gambill, B. A., A. I. Yashin, J. W. Vaupel, Z. Nanjo and T. Shigematsu 1986b. Cause specific mortality in Japan: Contour maps approach. IIASA Working Paper WP-86-078, Laxenburg, Austria: International Institute of Applied Systems Analysis. http://pure.iiasa. ac.at/id/eprint/2783/1/WP-86-078.pdf

Gompertz, B. 1825. On the nature of the function expressive of the law of human mortality, and on a new mode of determining the value of life contingencies. Philosophical Transactions of the Royal Society of London 115: 513-85.

Hamza-Cherif, A. 2011. L'évolution de la mortalité en Algérie de 1970 à 2007. Journal d'Epidémiologie et de Santé Publique 7: 21-31.

International Crisis Group 2001. The civil concord: A peace initiative wasted. ICG Africa Report, $\mathrm{N}^{\circ} 31$, Brussels. https://www.refworld.org/pdfid/3c0cbc604.pdf

Keiding, N. 1990. Statistical inference in the Lexis diagram. Philosophical Transactions of the Royal Society of London. Series A: Physical and Engineering Sciences 332(1627): 487-509. https://doi.org/10.1098/rsta.1990.0128

Kouaouci, A. and R. Saadi 2013. La reconstruction des dynamiques démographiques locales en Algérie (1987-2008) par des techniques d'estimation indirecte. Cahiers québécois de démographie 42(1): 101-132. https://doi.org/10.7202/1017099ar

Kruger, D. J. and R. M. Nesse 2004. Sexual selection and the male:female mortality ratio. Evolutionary Psychology 2: 66-85. https://doi.org/10.1177/147470490400200112

Lexis, W. 1875. Einleitung in die Theorie der Bevölkerungsstatistik. Strassburg: Karl J. Trübner.

McCaa, R. 1978. Chilean social and demographic history: sources, issues, and methods. Latin American Research Review 13(2): 104-126.

Martinez, L. 2003. Algérie: les nouveaux défis. Working Paper. SciencesPo. https://www. sciencespo.fr/ceri/sites/sciencespo.fr.ceri/files/artlm.pdf

Meslé, F. 2004. Gender gap in life expectancy: the reasons for a reduction of female advantage. Revue d'Épidémiologie et de Santé Publique 52(4): 333-352. https://doi.org/10.1016/ s0398-7620(04)99063-3

Minton, J. 2014. Real geographies and virtual landscapes: exploring the influence on place and space on mortality Lexis surfaces using shaded contour maps. Spatial and spatiotemporal epidemiology 10: 49-66. https://doi.org/10.1016/j.sste.2014.04.003

Minton, J., L. Vanderbloemen and D. Dorling 2013. Visualizing Europe's demographic scars with coplots and contour plots. International Journal of Epidemiology 42(4): 1164-1176. https://doi.org/10.1093/ije/dyt115

Minton, J., R. Shaw, M. A. Green, L. Vanderbloemen, F. Popham and G. McCartney 2017. Visualising and quantifying 'excess deaths' in Scotland compared with the rest of the UK and the rest of Western Europe. Journal of Epidemiology $\mathcal{E}$ Community Health 71(5): 461-467. https://doi.org/10.1136/jech-2016-207379 
Moriyama, I. M. 1990. Measurement of birth and death registration completeness. Technical Report $n^{\circ} 43$, Bethesda, Maryland, USA: International Institute for Vital Registration and Statistics. https://unstats.un.org/unsd/demographic-social/crvs/documents/IIVRS_papers/ IIVRS_paper43.pdf

Mouffok, A. 1984. L'état civil en Algérie: évolution de l'enregistrement des naissances et des décès infantiles de 1900 à 1981. Débats et Critique 9: 57-94.

Office National des Statistiques (ONS) 2003. Démographie algérienne 2002. Données Statistiques $n^{\circ} 375$, Alger, Algérie: Direction Technique chargée des statistiques de Population et de l'Emploi. https://www.ons.dz/IMG/pdf/DEMO2002.pdf

Office National des Statistiques (ONS) 2005. Démographie algérienne 2004. Données Statistiques $\mathrm{n}^{\circ} 419$, Alger, Algérie: Direction Technique chargée des statistiques de Population et de l'Emploi. https://www.ons.dz/IMG/pdf/DEMOGRAPHIE_2004.pdf

Office National des Statistiques (ONS) 2008. Démographie algérienne 2007. Données Statistiques $n^{\circ} 499$, Alger, Algérie: Direction Technique chargée des statistiques de Population et de l'Emploi. https://www.ons.dz/IMG/pdf/demographie_algerienne2007final.pdf

Office National des Statistiques (ONS) 2010. Démographie algérienne 2009. Données Statistiques $n^{\circ}$ 554, Alger, Algérie : Direction Technique chargée des statistiques de Population et de l'Emploi. https://www.ons.dz/IMG/pdf/demographie_algerienne2009f. pdf

Office National des Statistiques (ONS) 2012. Rétrospective 1962-2011 : Démographie. https://www.ons.dz/IMG/pdf/CH1-DEMOGRAPHIE.pdf

Office National des Statistiques (ONS) 2020. Démographie algérienne 2019. Données Statistiques n ${ }^{\circ} 80$, Alger, Algérie: Direction Technique chargée des statistiques de Population et de l'Emploi. https://www.ons.dz/IMG/pdf/demographie2019.pdf

Population Reference Bureau (PRB) 2020. 2020 World Population Data Sheet, Washington, DC: Population Reference Bureau. https://www.prb.org/wp-content/uploads/2020/07/ letter-booklet-2020-world-population.pdf

Preston, S. and Hill, K. 1980. Estimating the completeness of death registration. Population Studies 34(2): 349-366. https://doi.org/10.1080/00324728.1980.10410395

Preston, S., A. J. Coale, J. Trussell and M. Weinstein 1980. Estimating the completeness of reporting of adult deaths in populations that are approximately stable. Population Index 45(2): 179-202. https://doi.org/10.2307/2736122

Purdy, C., W. Weiss and H. Perry 2013.The Mortality Assessment for Health Programs (MAP) System: An NGO Field Manual for Registering Vital Events and Assessing Child Survival Outcomes Using the Care Group Model. $1^{\text {st }}$ Edition. Washington, D.C: CORE Group. https://pdf.usaid.gov/pdf_docs/PA00JMZS.pdf

Rau, R., C. Bohk-Ewald, M. M. Muszyńska and J. W. Vaupel 2018. Visualizing mortality dynamics in the Lexis diagram. Cham: Springer. https://doi.org/10.1007/978-3-31964820-0

Remund, A., C. G. Camarda and T. Riffe 2018. A cause-of-death decomposition of young adult excess mortality. Demography 55(3): 957-978. https://doi.org/10.1007/s13524-0180680-9 
Rey, G., A. Aouba, G. Pavillon, R. Hoffmann, I. Plug, R. Westerling, E. Jougla and J. Mackenbach 2011. Cause-specific mortality time series analysis: a general method to detect and correct for abrupt data production changes. Population Health Metrics 9(1): 52. https://doi.org/10.1186/1478-7954-9-52

Rigby, J. E. and D. Dorling 2007. Mortality in relation to sex in the affluent world. Journal of Epidemiology $\mathcal{F}$ Community Health 61(2): 159-164. https://doi.org/10.1136/jech.2006. 047381

Rogers, R. G., B. G. Everett, J. M. Saint Onge and P. M. Krueger 2010. Social, behavioral, and biological factors, and sex differences in mortality. Demography 47(3): 555-578. https://doi.org/10.1353/dem.0.0119

Salhi, M. 1984. L'évolution récente de la mortalité en Algérie (1965-1981). Working paper $\mathrm{N}^{\circ} 117$, Louvain-La-Neuve: Département de Démographie, Université Catholique de Louvain.

Secrétariat d'Etat au Plan 1975. Etude statistique nationale de la population, résultats de l'enquête démographique. Tome IV : Mortalité. Série 02 : Résultats, volume 7. Alger, Algérie : Secrétariat d'Etat au Plan.

Tabutin, D. 1991. High mortality rates among women in North Africa from 1965 to the present day - Descriptive aspects. Population 46(4): 833-854.

Tabutin, D. and B. Schoumaker 2005. The demography of the Arab world and the Middle East from the 1950s to the 2000s: A survey of changes and a statistical assessment. Population 60(5): 505-616. https://doi.org/10.2307/4148186

Tabutin, D., C. Gourbin and G. Beninguisse 2007. Surmortalité et santé des petites filles en Afrique. Tendances des années 1970 aux années 1990. In Genre et sociétés en Afrique. Implications pour le développement, ed T. Locoh 137-170. Paris: INED.

United Nations 1961. Demographic Yearbook. Thirteenth issue, Special Topic: Mortality Statistics. New York: Statistical Office of the United Nations. https://unstats.un.org/unsd/ demographic-social/products/dyb/dybsets/1961\%20DYB.pdf

United Nations 1982. Model life tables for developing countries. Population Studies, No. 77. New York: United Nations, Department of International Economic and Social Affairs.

Vanderbloemen, L., D. Dorling and J. Minton 2016. Visualising variation in mortality rates across the life course and by sex, USA and comparator states, 1933-2010. Jorunal of Epidemiology E Community Health 70(8): 826-831. http://doi.org/10.1136/jech-2014205226

Vaupel, J. W., B. A. Gambill and A. I. Yashin 1985. Contour maps of population surfaces. IIASA Research Report. IIASA, Laxenburg, Austria: WP-85-47. http://pure.iiasa.ac.at/id/ eprint/2653/1/WP-85-047.pdf

Vaupel, J. W., B. A. Gambill and A. I. Yashin 1987. Thousands of Data at a Glance: Shaded Contour Maps of Demographic Surfaces. IIASA Research Report RR-87-016, Laxenburg, Austria: International Institute of Applied Systems Analysis. http://pure.iiasa.ac.at/id/ eprint/2905/1/RR-87-016.pdf

Vékás, P. 2020. Rotation of the age pattern of mortality improvements in the European Union. Central European Journal of Operations Research 28(3): 1031-1048. https://doi.org/10. 1007/s10100-019-00617-0 
Wilmoth, J. R. 1985. Identifiable Age, Period, and Cohort Effects: An Exploratory Approach Applied to Italian Female Mortality. IIASA Working Paper WP-85-069. Laxenburg, Austria: International Institute of Applied Systems Analysis. http://pure.iiasa.ac.at/id/ eprint/2632/1/WP-85-069.pdf

Wisser, O. and J. W. Vaupel 2014. The sex differential in mortality: a historical comparison of the adult-age pattern of the ratio and the difference. MPIDR Working Paper WP 2014-005. Rostock: Max Planck Institute for Demographic Research. https://www.demogr.mpg.de/ papers/working/wp-2014-005.pdf

Open Access This article is published under the terms of the Creative Commons Attribution 4.0 International License (https://creativecommons.org/licenses/by/4.0/) that allows the sharing, use and adaptation in any medium, provided that the user gives appropriate credit, provides a link to the license, and indicates if changes were made. 